\title{
Titanium allergy or not? "Impurity" of titanium implant materials
}

\author{
Thomas Harloff ${ }^{1}$, Wolfgang Hönle ${ }^{2}$, Ulrich Holzwarth ${ }^{3}$, Rainer Bader ${ }^{4}$, Peter Thomas ${ }^{5}$, \\ Alexander Schuh ${ }^{1}$ \\ ${ }^{1}$ Research Unit, Neumarkt Clinical Center, Neumarkt, Germany \\ ${ }^{2}$ Orthopedic Clinic Neumarkt, Neumarkt, Germany \\ ${ }^{3}$ MedTitan, Erlangen, Germany \\ ${ }^{4}$ Orthopedic Clinic and Polyclinic, University of Rostock, Rostock, Germany \\ ${ }^{5}$ Clinic and Polyclinic for Dermatology and Allergology of the Ludwig-Maximilians-University of Munich, Munich, Germany; \\ Alexander.Schuh@klinikum.neumarkt.de
}

Received 25 December 2009; revised 26 January 2010; accepted 30 January 2010.

\section{ABSTRACT}

For patients suffering from allergies to nickel, chrome and cobalt, titanium implants are the implants of choice. Nevertheless, titanium implant sensitivity has been reported in the form of "allergies" and an increasing number of patients are confused. This paper aims to use spectral analysis as a diagnostic tool for analyzing different titanium implant alloys in order to determine the percentage of the alloy components and additions that are known to cause allergies. Different materials, such as sponge titanium, TiAl6Nb7, Ti21SRx, TiAl6V4 [forged alloy], TiAI6V4 [cast alloy], TMZF, pure titanium [c. p. 1] and iodide titanium were analyzed for the presence of the elements that have been associated with allergic reactions using spectral analysis. All the implant material samples contained traceable amounts of $\mathrm{Be}, \mathrm{Cd}, \mathrm{Co}$, up to a maximum of 0.001 percent by weight [wt.\%], $\mathrm{Cr}$ up to $0.033 \mathrm{wt} . \%$, Cu up to $0.007 \mathrm{wt} \%$, Hf up to 0.035 wt. \%, Mn up to 0.007 wt.\%, Ni up to 0.031 wt.\%, and $\mathrm{Pd}$ up to 0.001 wt.\%. This paper demonstrates that all the investigated implant material samples contained a low but consistent percentage of components that have been associated with allergies. For example, low nickel contents are related to the manufacturing process and are completely dissolved in the titanium grid. Therefore, they can virtually be classified as "impurities". Under certain circumstances, these small amounts may be sufficient to trigger allergic reactions in patients suffering from the corresponding allergies, such as a nickel, palladium or chrome allergy.

Keywords: Allergy; Implant; Nickel; Spectral
Analysis; Titanium

\section{INTRODUCTION}

Numerous studies on allergic reactions to synthetic materials have been carried out, in particular on allergic reactions to metallic components that are also used in orthopedic surgery. In case histories, localized or generalized eczemas, urticaria, persistent swelling, sterile osteomyelitis and cases of aseptic implant loosening are described as examples of allergic reactions to metal implants [1-28]. Nickel, cobalt and chrome are the classic contact allergens [1,2,11,29-32]. However, in contrast to the sensitization ratio of up to 12 percent of the general population to nickel and of up to 5 percent to cobalt and chrome [24,32], only a few cases of allergies to implant materials have been documented. Precise details on the frequency of such reactions are presently not available. Furthermore, up to now, the frequency of allergic reactions occurring in the peri-implant region, without any prior patch test reactions, has not been established. For example, inflammatory infiltrations of the peri-implant region displaying characteristics of late-type allergic reactions were found in a number of patients undergoing revision operations related to complications [2]. Thomas [24] and Willert [27] published cases of endoprosthesis loosening with accompanying T-lymphocyte-dominated immune reactions in the peri-implant region. In the 1970s, obvious allergic reactions to the cobalt-chrome alloy components of the McKee-Farrar prosthesis underwent scrutiny for the first time [3,11]. In case of a nickel allergy, individual responsiveness can be very diverse, with even minute quantities of nickel causing contact eczemas in sensitive patients [3,11,32]. Their high resistance to corrosion, the absence of any carcinogenic risk, their excellent bio-compatibility and their 
lack of sensitization make titanium implants or titanium alloy implants the recommended alternative for patients with nickel, cobalt or chrome allergies [33,34]. Admittedly, there are also reports of incompatibility reactions to titanium materials [10,25,35-42]. In his study, Walsh [42] found several eyeglass frames made of a titanium alloy to contain nickel traces. Likewise, Suhonen [41] documented allergic contact dermatitis caused by titanium eyeglass frames. However, in Suhonen's case, palladium was established as the causative factor.

In his comparative histological and immuno-histochemical analysis of tissues surrounding titanium implants $[\mathrm{n}=23]$ and implant steel $[\mathrm{n}=8]$, Thewes [23] documented the presence of peri-vascular infiltrations, Langerhans cells, $\mathrm{T}$ helper cells, $\mathrm{T}$ suppressor cells, monocytes, macrophages and memory cells, and did not find any statistically significant difference between both groups of implants. Thewes concluded that a metal sensitization to both steel implants and titanium implants is possible. Yamauchi [43] described an eczema reaction in connection with a pacemaker made of titanium. Lalor et al. [38] analyzed the granuloma tissue of five patients that had undergone a revision operation following an aseptic prosthesis loosening. The granuloma tissue was found to contain primarily titanium. Each of the five patients subjected to scratch testing using diluted solutions of titanium salts yielded negative results. However, two of the patients displayed a positive skin reaction to titanium-containing ointments.

These above mentioned reports led to more and more confused patients. This paper aims to examine different titanium implant alloys in respect to impurity with components that are known to potentially cause allergies.

\section{MATERIAL AND METHOD}

A Spectrolab spectral analysis unit from the Spectro company [Kleve, Germany] was used to study the titanium materials [listed in Table 1 with their respective producers]. Prior to the test, the optical analysis unit was calibrated using calibrated samples, the chemical com

Table 1. Materials analyzed.

\begin{tabular}{ll}
\hline Materials & Producer/Supplier \\
\hline Sponge titanium & Source Japan \\
Sponge titanium & Source Russia \\
TiAl6Nb7 & TIMET USA \\
Ti21SRx & TIMET Laboratories, Henderson, \\
TiAl6V4 & USA \\
FG-TiAl6V4 & Allvac Teledyne, Monroe, USA \\
TMZF & ASTM F 1108 \\
Pure titanium rod, Ti-2 & Stryker \\
Pure titanium plate, Ti-1 & TIMET \\
Iodide titanium & Deutsche Titan \\
\hline
\end{tabular}

position of which was determined via optical spectral analysis by sparking sample slices [with a diameter of 6-60 $\mathrm{mm}$ and a thickness of $6 \mathrm{~mm}$ ] under argon atmosphere using a $6 \mathrm{~mm}$ ceramic aperture. In this particular case, the measuring depth obtained by sparking is 0.5 $\mathrm{mm}$, making the thickness of the examined samples irrelevant. The described method pertains to a material analysis and not to a layer analysis. A detailed analysis was performed on pure titanium slices with a diameter of 6 and $12 \mathrm{~mm}$.

TiAl6V4 slices with a diameter of $10,16,22,35$ and $60 \mathrm{~mm}$, respectively, and TiAl6Nb7 slices with a diameter of 14.5, 22 and $28 \mathrm{~mm}$, respectively. Samples of rods with different diameters were analyzed because the various titanium alloys of the individual manufacturers are available with different diameters. The analyses were performed according to the established and [statistically] recognized measuring methods used in material science for determining alloy components. Since it has to be assumed that the material is homogeneous over the entire length of the respective [titanium or titanium alloy] rod, only a $6 \mathrm{~mm}$ thick sample slice was analyzed in each individual case. Three measurements and a final verification measurement were conducted. Each of the results indicated corresponds to the average value obtained from the three measurements, with the standard deviation being less than 0.01 percent by weight.

\section{RESULTS}

The results of the spectral analysis are shown in Table 2 . All the implant material samples contained traceable amounts of $\mathrm{Be}, \mathrm{Cd}, \mathrm{Co}$, up to a maximum of 0.001 percent by weight, $\mathrm{Cr}$, up to a maximum of 0.033 percent by weight, $\mathrm{Cu}$, up to a maximum of 0.007 percent by weight, Hf, up to a maximum of 0.035 percent by weight, $\mathrm{Mn}$, up to a maximum of 0.007 percent by weight, $\mathrm{Ni}$, up to a maximum of 0.031 percent by weight, and $\mathrm{Pd}$, up to a maximum of 0.001 percent by weight [Table 2].

\section{DISCUSSION}

There is an increasing number of reports of incompatibility reactions to titanium materials [10,25,35-42]. All the titanium materials examined in the present study clearly showed consistently traceable amounts of additional components, such as nickel. Although contents between 0.01 and 0.034 percent by weight are considered to be insignificant from a metallurgic perspective, they are subject to discussion in the context of the high nickel sensitization rate present in the general population. The levels of additions found in iodide titanium correspond to the expected levels and demonstrate that, in this context, the absolutely lowest traces of nickel that are technologically possible can be adhered to, namely close 
Table 2. Analysis results (n.t.: not traceable).

\begin{tabular}{|c|c|c|c|c|c|c|c|c|c|c|c|c|c|}
\hline Material & \multicolumn{13}{|c|}{ Analysis values in \% by weight } \\
\hline & $\mathrm{Al}$ & $\mathrm{Be}$ & $\mathrm{Cd}$ & $\mathrm{Co}$ & $\mathrm{Cr}$ & $\mathrm{Cu}$ & $\mathrm{Fe}$ & Hf & $\mathrm{Mn}$ & Mo & $\mathrm{Ni}$ & $\mathrm{Pd}$ & $\mathrm{V}$ \\
\hline Sponge titanium (Japan) & 0,001 & 0,001 & 0,001 & 0,001 & 0,002 & 0,007 & 0,001 & 0,001 & 0,001 & 0,001 & 0,008 & 0,001 & 0,001 \\
\hline Sponge titanium (Russia) & 0,001 & 0,001 & 0,001 & 0,001 & 0,001 & 0,001 & 0,002 & 0,001 & 0,007 & 0,001 & 0,001 & 0,001 & 0,001 \\
\hline TiAl6Nb7 & 5,980 & 0,001 & 0,001 & 0,001 & 0,011 & 0,001 & 0,150 & 0,001 & 0,002 & 0,001 & 0,014 & 0,001 & 0,001 \\
\hline Ti21SRx & 0,005 & 0,001 & 0,001 & 0,001 & 0,005 & $\mathrm{n} n$. & 0,037 & 0,001 & 0,002 & 15,00 & 0,017 & 0,001 & 0,001 \\
\hline TiAl6V4 & 5,930 & 0,001 & 0,001 & 0,001 & 0,033 & 0,001 & 0,160 & 0,001 & 0,004 & 0,002 & 0,031 & 0,001 & 3,880 \\
\hline FG-TiAl6V4 ASTM F 1108 & 6,20 & 0,0001 & 0,0001 & 0,001 & 0,012 & 0,001 & 0,170 & 0,001 & 0,001 & 0,001 & 0,011 & 0,001 & 4,15 \\
\hline $\mathrm{TMZF}$ & 0,005 & 0,001 & 0,001 & 0,001 & 0,008 & 0,003 & 2,090 & 0,035 & 0,001 & 12,00 & 0,013 & 0,001 & 0,002 \\
\hline Pure titanium rod, Ti-2, Timet & 0,021 & 0,001 & 0,001 & 0,001 & 0,014 & 0,001 & 0,041 & 0,001 & 0,002 & 0,001 & 0,013 & 0,001 & 0,012 \\
\hline $\begin{array}{c}\text { Pure titanium Ti-1, Plate } \\
\text { (Deutsche Titan) }\end{array}$ & 0,004 & 0,001 & 0,001 & 0,001 & 0,012 & 0,001 & 0,028 & 0,001 & 0,001 & 0,001 & 0,012 & 0,001 & 0,001 \\
\hline
\end{tabular}

to the detection limit of less than 0.001 percent by weight. All the other samples, independent of the producer, were always found to contain a consistently low percentage of additions, such as nickel, following their further processing into rods of different sizes [diameters between 6 and $60 \mathrm{~mm}$ were analyzed]. Numerous publications deal with hypersensitivity reactions to osteosynthesis materials used in the treatment of fractures, the majority of these materials being stainless steel implants $[7,19,32]$.

An immunological response to metals [partly as an exaggerated allergic reaction] is discussed to be the cause of impaired wound healing or the delayed healing of fractures [19]. Allergic reactions to orthopedic implants can thus also necessitate the removal of the implant [24]. Lymphocyte infiltration was discovered in the peri-prosthetic tissue, indicating T-lymphocyte-related inflammation components [25-28]. This lymphocyte infiltration can be considered a component of a delayed hypersensitivity reaction [DTH, Delayed Type Hypersensitivity] $[2,26,27]$. Vasculitis with lymphocyte infiltration of the vascular walls and substantial fibrin exudation have been described [11,27,32]. Nickel, cobalt and chrome can cause allergic reactions in humans [2,19,31], with nickel being one of the most common contact allergens. The average sensitization ratio in the general population lies between 2 percent and 12 percent, depending on age, gender and living conditions. In addition to the typical findings, such as hand eczeme, uncommon manifestations, such as pseudo-lymphomas or implantassociated intolerance reactions, are also known to occur [24]. Many aspects of skin allergies have already been analyzed, such as thresholds above which allergens, such as nickel, chrome or cobalt trigger skin reactions, the use of standardized provocation testing for the detection of an allergy [patch test], [immuno-] histological characteristics of such reactions, tracking elements, such as CLA [cutaneous leukocyte antigen], which allow sensitized
T-cells to migrate into the skin, and the diminishing reactivity following the avoidance of the allergens for many years which leads to problems only after repeated fresh contact with the respective allergen [booster], e.g. in case of the repeated wear of fashion jewelry. Accordingly, the "Nickel Directive" [31], which applies to items that have a direct and prolonged contact with the skin, determines that a maximum of $0.5 \mu \mathrm{g} \mathrm{nickel} / \mathrm{cm}^{2} /$ week can be released and limits the nickel contents in piercing metals to 0.05 percent. However, such guidelines do not yet exist for implants or implant materials. In a study carried out on 242 patients, Swiontkowski et al. [22] reported a sensitization prevalence of 0.2 percent for chromium, 1.3 percent for nickel and 1.8 percent for cobalt. Subsequent to the implantation of orthopedic implants, the sensitization rate increased to 2.7 percent for chromium, 3.8 percent for nickel and 3.8 percent for cobalt. In many cases, only minute amounts of nickel suffice to trigger allergic reactions, such as contact eczemas [32]. Therefore, titanium implants or titaniumalloy implants are often used as an alternative for patients suffering from nickel, chrome or cobalt allergies [30]. Duchna [10] conducted a study on 112 patients and did not find any allergic reactions that were associated with titanium implants. The biocompatibility of titanium materials [32] is based on the passivation of its surface. In its intact state, this surface consists of non-conductive titanium oxide, a bio-inert material that chemically corresponds to ceramics. When corrosion occurs due to an electron flow, an interaction between the body and the implant takes place. In essence, these interactions are dependent on the insulation provided by the oxide layers and thus dependent on the dielectric constant and therefore on the insulating effect of the metal oxides. The higher the dielectric constant is, the better the insulating effect and the resulting stability in vivo. Depending on the oxide type, titanium oxide has a value between $\varepsilon=$ 48 and $\varepsilon=110$, with water having a value of $\varepsilon=78$ [32]. 
In contrast, the dielectric constant for cobalt oxide and nickel oxide is not measurable [32]. Therefore, an interaction with body electrolytes is likely to occur on a much larger scale than is the case for metals belonging to the refractory group [oxide formation in milliseconds], such as titanium, niobium, tantalum, vanadium and their alloys. Alternatively, "ceramic" coatings, such as titanium-niobium-oxynitride, can be used to artificially protect implant alloys against corrosion.

\section{CONCLUSIONS}

Our results demonstrate that titanium materials contain a small yet consistent percentage of detectable impurities, such as the elements $\mathrm{Al}, \mathrm{Be}, \mathrm{Cd}, \mathrm{Co}, \mathrm{Cr}, \mathrm{Cu}, \mathrm{Fe}, \mathrm{Hf}, \mathrm{Mn}$, Mo, Ni, Pd and V. All the implant material samples thus contain a consistent yet low percentage of components to which allergies have been attributed. Under specific circumstances, even small amounts of elements, such as palladium, nickel or chromium, suffice to trigger an allergic reaction in patients suffering from the corresponding allergies. However, these allergic reactions would not be directly attributable to titanium or its alloys, but rather to the impurities contained therein. Additional research on the release of the alloy components and the reaction thresholds of the afflicted patients is urgently required. Parallel to this research, alternative production processes should be evaluated by the companies producing these metals in order to produce pure titanium and titanium alloys containing fewer impurities, for use in the human body. Titanium continues to be the implant material of choice for patients suffering from allergic reactions to cement-free implants.

\section{REFERENCES}

[1] Banfield, C.C., Basketter, D.A. and Powell, S.M. (1998) Cutaneous reactivity of the hands in nickel-sensitive patients with hand eczema. Contact Dermatitis, 38, 316-318.

[2] Baur, W., Hönle, W. and Schuh, A. (2005) Pathological findings in tissue surrounding revised metal/metal articulations. Der Orthopäde, 34, 225-233.

[3] Benson, M.K., Goodwin, P.G. and Brostoff, J. (1975) Metal sensitivity in patients with joint replacement arthroplasties. British Medical Journal, 15, 374-375.

[4] Campbell, P., Mirra, J., Doorn, P., Mills, B., Alim, R. and Catelas, I. (2001) Histopathology of metal-on-metal hip joint tissues. In Rieker Ed., World Tribology Forum in Arthroplasty, 167-180.

[5] Carlsson, A.S., Magnusson, B. and Moller, H. (1980) Metal sensitivity in patients with metal-to-plastic total hip arthroplasties. Acta Orthopaedica Scandinavica, 51, 57-62.

[6] Christiansen, K., Holmes, K. and Zilko, P.J. (1979) Metal sensitivity causing loosened joint prosthesis. Annals of Rheumatic Diseases, 38, 476-480.

[7] Cramers, M. and Lucht, U. (1977) Metal sensitivity in patients treated for tibial fractures with plates of stainless steel. Acta Orthopaedica Scandinavica, 48, 245-249.

[8] Davies, A.P., Willert, H.G., Campbell, P.A., Learmonth, I.D. and Case, C.P. (2005) An unusual lymphocytic perivascular infiltration in tissues around contemporary metal-on-metal joint replacements. The Journal of Bone and Joint Surgery-American Volome, 87, 18-27.

[9] Doorn, P.F., Mirra, J.M., Campbell, P.A. and Amstutz, H.C. (1996) Tissue reaction to metal on metal total hip prostheses. Clinical Orthopaedics, 329 (Suppl.), S187205.

[10] Duchna, H.W., Nowack, U., Merget, R., Muhr, G. and Schultze-Werninghaus, G. (1998) Prospective study of the significance of contact sensitization caused by metal implants. Zentralbl Chir, 123, 1271-1276.

[11] Elves, M.W., Wilson, J.N., Scales, J.T. and Kemp, H.B. (1975) Incidence of metal sensitivity in patients with total joint replacements. British Medical Journal, 15, 376-378.

[12] Gawkrodger, D.J. (2003) Metal sensitivities and orthopaedic implants revisited: The potential for metal allergy with the new metal-on-metal joint prostheses. British Journal of Dermatology, 148, 1089-1093.

[13] Goodman, S.B. (1996) Does the immune system play a role in loosening and osteolysis of total joint replacements? Journal of Long-Term Effects of Medical Implants, 6, 91-101.

[14] Hallab, N., Merritt, K. and Jacobs, J.J. (2001) Metal sensitivity in patients with orthopaedic implants. The Journal of Bone and Joint Surgery, 83-A(3), 428-436.

[15] Hallab, N.J., Anderson, S., Stafford, T., Glant, T. and Jacobs, J.J. (2005) Lymphocyte responses in patients with total hip arthroplasty. Journal of Orthopaedic Surgery and Research, 23, 384-391.

[16] Kaplan, K., Della Valle, C.J., Haines, K., et al. (2002) Preoperative identification of a bone-cement allergy in a patient undergoing total knee arthroplasty. The Journal of Arthroplasty, 17, 788-791.

[17] Kubba, R., Taylor, J.S. and Marks, K.E. (1981) Cutaneous complications of orthopedic implants. A two-year prospective study. Archives of Dermatology, 117, 554560.

[18] McKenzie, A.W., Aitken, C.V. and Ridsdill-Smith, R. (1967) Urticaria after insertion of Smith-Petersen Vitallium nail. British Medical Journal, 4, 36.

[19] Merritt, K. and Rodrigo, J.J. (1996) Immune response to synthetic materials. Sensitization of patients receiving orthopaedic implants. Clinical Orthopaedics, 326, 71-79.

[20] Munro-Ashman, D. and Miller, A.J. (1976) Rejection of metal to metal prosthesis and skin sensitivity to cobalt. Contact Dermatitis, 2, 65-67.

[21] Schuh, A., Thomas, P., Holzwarth, U., Reinhold, R., Zeiler, G. and Mahler, V. (2006) Allergic reaction to components of bone cement after total knee arthroplasty. Zentralbl Chir, 131, 429-31.

[22] Swiontkowski, M.F., Agel, J., Schwappach, J., McNair, P. and Welch, M. (2001) Cutaneous metal sensitivity in patients with orthopaedic injuries. Journal of Orthopaedic Trauma, 15, 86-89.

[23] Thewes, M., Kretschmer, R., Gfesser, M., Rakoski, J., Nerlich, M., Borelli, S., et al. (2001) Immunohistochemcical characterization of the perivascular infiltrates cells 
in tissues adjacent to stainless steel implants compared with titanium implants. Archives of Orthopaedic and Trauma Surgery, 121, 223-226.

[24] Thomas, P. (2003) Allergic reactions to implant materials. Der Orthopäde, 32, 60-64.

[25] Thomas, P. (2006) Impaired fracture healing and eczema from titanium based osteosynthesis with corresponding T-cell hyperresponsiveness in vitro: A case of titanium hypersensitivity? Contact Dermatitis, 55, 199-202.

[26] Thomas, P., Thomas, M., Summer, B., Naumann, T., Sander, C.A. and Przybilla, B. (2000) Intolerance of osteosynthesis material: Evidence of dichromate contact allergy with concomitant oligoklonal T-cell infiltrate and TH1-type cytokine expression in the peri-implantar tissue. Allergy, 55, 969-972.

[27] Willert, H.G., Buchhorn, G.H., Fayyazi, A., Flury, R., Windler, M., Koster, G., et al. (2005) Metal-on-metal bearings and hypersensitivity in patients with artificial hip joints. A clinical and histomorphological study. The Journal of Bone and Joint Surgery-American Volome, 87, 28-36.

[28] Willert, H.G., Buchhorn, G.H., Gobel, D., Koster, G., Schaffner, S., Schenk, R., et al. (1996) Wear behavior and histopathology of classic cemented metal on metal hip endoprostheses. Clinical Orthopaedics and Related Research, 329 (Suppl.), 160-186.

[29] Gawkrodger, D.J. (1996) Nickel dermatitis: How much nickel is safe? Contact Dermatitis, 35, 267-271.

[30] Kreibich, D.N., Moran, C.G., Delves, H.T., Owen, T.D. and Pinder, I.M. (2006) Systemic release of cobalt and chromium after uncemented total hip replacement. The Journal of Bone and Joint Surgery-British Volome, 78, 18-21.

[31] Liden, C. and Norberg, K. (2005) Nickel on the Swedish market. Follow-up after implementation of the Nickel Directive. Contact Dermatitis, 52, 29-35.

[32] Schuh, A., Thomas, P., Kachler, W., Göske, J., Wagner,
L., Holzwarth, U., et al. (2005) Allergic potential of titanium implants. Der Orthopäde, 34, 327-333.

[33] Farronato, G., Tirafili, C., Alicino, C. and Santoro, F. (2002) Titanium appliances for allergic patients. Journal of Clinical Orthopaedics, 36, 676-679.

[34] Tan, M. and Suzuki, H. (1995) Usefulness of titanium implants for systemic contact dermatitis due to orthopaedic prostheses. Contact Dermatitis, 33, 202.

[35] Basketter, D.A., Whittle, E. and Monk, B. (2000) Possible allergy to complex titanium salt. Contact Dermatitis, 42, 310-311.

[36] Bircher, A.J. and Stern, W.B. (2001) Allergic contact dermatitis from "titanium" spectacle frames. Contact Dermatitis, 45, 244-245.

[37] Breton, J.L., Louis, J.M. and Garnier, G. (1992) Asthma caused by hard metals: Responsibility of titanium. Presse Medicale Journal, 21, 997.

[38] Lalor, P.A., Revell, P.A., Gray, A.B., Wright, S., Railton, G.T. and Freeman, M.A. (1991) Sensitivity to titanium. A cause of implant failure? The Journal of Bone and Joint Surgery-British Volome, 73, 25-28.

[39] Matthew, I. and Frame, J.W. (1998) Allergic responses to titanium. Journal of Oral and Maxillofacial Surgery, 56, 1466-1467.

[40] Mitchell, D.L., Synnott, S.A. and VanDercreek, J.A. (1990) Tissue reaction involving an intraoral skin graft and CP titanium abutments: A clinical report. The International Journal of Oral \& Maxillofacial Implants, 5, 79-84.

[41] Suhonen, R. and Kanerva, L. (2001) Allergic contact dermatitis caused by palladium on titanium spectacle frames. Contact Dermatitis, 44, 257-258.

[42] Walsh, G. and Mitchell, J.W. (2002) Free surface nickel in CE-marked and non-CE-marked spectacle frames. Ophthalmic and Physiological Optics, 22, 166-171.

[43] Yamauchi, R., Morita, A. and Tsuji, T. (2000) Pacemaker dermatitis from titanium. Contact Dermatitis, 42, 52-53. 